\title{
The role of rhyme awareness in learning to read a regular orthography
}

\author{
Heinz Wimmer* and Karin Landerl \\ University of Salzburg, Hellbrunnerstrasse 34, A-5020 Salzburg, Austria \\ Wolfgang Schneider \\ Max-Planck Institute for Psychological Research, Munich and University of Würzburg
}

\begin{abstract}
The present research examined whether children's awareness of phonological similarities between words with respect to rhyme and consonantal word onset is of the same importance for learning to read German as it was found to be for learning to read English. In two longitudinal studies differences in phonological sensitivity among children before learning to read (at age 6 to 7) were tested with versions of Bradley \& Bryant's (1985) oddity detection task. Children's reading and spelling achievements were tested about one year later at the end of grade one, and again at around the age of 10 . The main finding was a developmental change in the predictive relationship of rhyme and word-onset awareness. Rhyme awareness was only minimally predictive for reading and spelling achievement at the end of grade one, but gained substantially in predictive importance for reading and spelling achievement in grades three and four. No such predictive improvement was observed for word-onset awareness. It is proposed that rhyme awareness is initially of little importance, because in the first phase of learning to read German children rely heavily on indirect word recognition via grapheme-phoneme translation and blending. The gain in the predictive importance of rhyme awareness is explained by its helpful effect on the establishment of mental representations of written words. Such mental representations allow fast, direct word recognition and orthographically correct spellings. Awareness of larger phonological units is helpful for the efficient establishment of such representations, by allowing connections of recurring grapheme clusters in written words with phonology.
\end{abstract}

Bryant and colleagues, in Oxford, demonstrated that learning to read English is affected in important ways by children's awareness of phonological similarities between spoken words. In a seminal study Bradley \& Bryant (1978) found that backward readers tended to be far worse at detecting and producing rhymes than normal readers. Subsequent developmental studies found that preschool differences in detecting rhyme and wordonset similarities were predictive for later differences in learning to read (Bradley \& Bryant, 1985; Bryant, MacLean, Bradley \& Crossland, 1990). With their oddity detection task, Bradley \& Bryant (1985) tested a large number of children at 4 or 5 years of age (all non-readers). Children had to identify, for example, in items such as 'lot''cot'-'hat'-'pot' that 'hat' was the odd word (rhyme detection). In items such as 'bud''bun'-'bus'-'rug' children had to determine that 'rug' was odd with respect to the word-

* Requests for reprints. 
onset, that is, the consonant(s) before the vowel (word-onset detection). About three years later when children were between 8 and 9 years of age their achievement in reading, spelling and mathematics was tested with standardized tests. Results showed that rhyme and word-onset detection was specifically related to reading and spelling achievement (correlations around .40), but not to skills in mathematics. The specific predictions of reading and spelling were retained when IQ was partialled out. Bryant et al. (1990) replicated and extended these results. The predictions from rhyme and word-onset detection tested at the age of $4 \frac{1}{2}$ years to reading and spelling achievement two years later were surprisingly high (correlation around .70). Furthermore, it was found that rhyme and word-onset awareness predicted reading even when differences in phoneme awareness were controlled for. This was not the case for spelling differences.

Goswami analysed how rhyme and word-onset awareness may become important in the early phase of learning to read. In a set of experimental studies Goswami (1986, 1988, 1991), showed that early in learning to read, children, to some extent, spontaneously base their reading of new words on rhyme and word-onset-based analogies of known words. For example, children showed transfer from the known word beak to the new word peak (rhyming) or from the known word flan to the new word flop (same onset). Rhymebased analogies were easier than word-onset-based analogies. Furthermore, Goswami (1990) showed that children who performed well on Bradley \& Bryant's rhyme oddity detection task were better at using such phonology-based analogies. A study by Kirtley, Bryant, MacLean \& Bradley (1989) showed that oddity detection in the Bradley \& Bryant task is indeed based on word onsets and rhymes and not on single phonemes.

The question addressed by the present research was whether rhyme and word-onset awareness is of similar importance in learning to read German as it was found to be in learning to read English. The critical difference between English and German is the higher consistency of the German writing system at the level of grapheme-phoneme correspondences. This is particularly the case for vowel graphemes. To illustrate, in cat, ball and garden the as receive different pronunciations, while the $a$ is always pronounced $/ a /$ in the corresponding German words Katze, Ball and Garten. Reading instruction, for German children in general, and certainly for the children in the present research, makes use of the consistent grapheme-phoneme correspondences by relying on a phonics approach. The key aim is to induce children to assemble pronunciations via graphemephoneme translation and blending. Given the consistency of the orthography, this indirect word recognition strategy is quite effective, since the assembled pronunciations tend to be close to the correct ones. Two recent studies which compared reading strategies of German and English children, in fact, revealed much stronger reliance on indirect word recognition among the young German readers than among the young English readers (Wimmer \& Frith, 1992; Wimmer \& Goswami, 1994). In both studies it was found that German children have much less difficulty than English children reading non-words for which reading is equivalent to assembling pronunciations. Furthermore, the correlation between reading time for words and non-words was close to perfect for the young German readers, but not for the young English readers (Wimmer \& Goswami, 1994). Particularly indicative of the reliance on indirect word recognition of the young German readers was the finding by Wimmer \& Frith (1992) that in a lexical decision task, young German readers were much more inclined than young English readers to misjudge as correct the non-existent spellings which sound like existing words. 
The difference in reading strategies between young German and young English children, and particularly the ease with which German children acquire an indirect word recognition strategy, suggests that rhyme and word-onset awareness may be of little importance, at least for the early phases of learning to read German. Obviously, there is little need to use rhyme- and word-onset-based analogies in the reading of new words when pronunciations can be easily assembled via grapheme-phoneme translation and blending. However, it seems quite possible that rhyme and word-onset awareness become important in later phases of reading and writing acquisition when fluent reading and orthographically correct spelling are expected. These achievements depend on memory representations of written words, and such mental representations may be more easily established when graphemes can be grouped and connected to larger phonological segments of words such as rhymes or word onsets. (A more detailed explication of this view is given in the Discussion.)

The present research examined these theoretical possibilities in two longitudinal studies. Children were tested with German versions of Bradley \& Bryant's rhyme and onset oddity detection task before reading instruction began. In Study 1 children were tested immediately after school entrance, and in Study 2 children were tested at the end of the last year of kindergarten. For the interpretation of these assessments of phonological awareness it is important to note that there is no reading preparation involving letters in Austrian and German kindergartens. It should also be noted that at the first assessment the children were considerably older than children in the Oxford studies, since Austrian and German children must reach 6 years of age before entering their first school year in the autumn. In both studies reading and spelling achievement were tested first at the end of grade one and again at the end of grade three (Study 1) or grade four (Study 2). At these two assessment points children can be expected to be at quite different levels of reading and spelling achievement. Since there is no reading preparation with letters in kindergarten and since teaching proceeds rather slowly in first grade, children at the end of grade one are rather inexperienced readers. What they typically have acquired is the ability to assemble pronunciations of words, but, quite often, in a slow, laborious way. In contrast, at the end of grade three, children are expected to read long texts fluently and effortlessly and heavy emphasis is placed on orthographically correct spelling. It should be noted that even in the rather regular German orthography, correct spellings often do not result simply from phonemegrapheme translation. One reason for this is that regularity is greater in the direction from graphemes to phonemes than vice versa. For example, there are several ways in which long vowels are orthographically represented (e.g. Boot vs. Bobne), so the correct spellings require memory representation for the written words. Testing children both at the end of grade one and at the end of grade three allowed examination of the different effects of phonological awareness on both early and advanced levels of reading and spelling competence.

We were also interested in whether early phonological awareness differentially affects the reading and writing of words in contrast to the reading and writing of non-words. Therefore, in Study 1 both words and non-words were presented at the end of grade one and at the end of grade three. Phonological processes are assumed to be more heavily involved in the reading and writing of non-words, for which, by definition, there can be no direct associations between spelling patterns and pronunciations. 


\title{
STUDY 1
}

\author{
Method
}

\section{Subjects}

Forty-five children ( 19 girls and 26 boys) who attended three different first-grade classes of elementary schools in the city of Salzburg participated in this study. Children were first tested one month after they had started school in the autumn. At that time no reading instruction had yet taken place since the first letters were introduced after about two months of schooling. Children's mean age at first testing was 6:11 years (range: $6: 1-7: 11$ ), their mean intelligence, measured by Raven's Coloured Progressive Matrices, was 108 (range: 93-134). About seven months later, at the end of grade one, and again at the end of grade three (mean age $=9: 9$ ), children's reading and spelling was assessed.

\section{Oddity detection task}

The present version of the rhyme and onset oddity detection task was modelled after the task version used by Bradley \& Bryant (1985) for their group of 5-year-olds. Appendix A shows the items of the three tasks, which, following Bradley \& Bryant's terminology were labelled first-sound, middle-sound and end-sound tasks. This terminology is somewhat inappropriate, since in both the middle-sound task (e.g. 'Mund'-'rund'-'Mond'-'Hund') and the end-sound task (e.g. 'Meer'-'Mebl'-'sehr'-'leer') it is the rhyme similarity between the majority of the words which is violated by the odd word. In the first-sound task (e.g. 'Bach'-'Bahn'-'Dacb'-'Bad') it is the onset similarity which is violated by the odd word. As is evident from Appendix A all words are monosyllabic, the majority conforming to a consonant-vowelconsonant (CVC) structure. In contrast to Bradley \& Bryant (1985) we were not able to find enough $\mathrm{CVC}$ words for all items. Therefore, some of the words begin or end with a consonant cluster. Since the present children were about two years older than the children for whom Bradley \& Bryant had designed their task, a deliberate attempt was made to increase the difficulty of oddity detection. This was done by making the oddity of the odd word less salient. In the case of the rhyme items we attempted to achieve lesser salience of the odd word by selecting it in such a way that it had the same onset as one of the three rhyming words (example: ' $M$ und'-'rund'-'Mond'-'Hund'). Similarly, in the case of the onset items the odd word was selected in such a way that it rhymed with one of the alliterating words (e.g. 'Bach''Bahn'-'Dach'-'Bad').

Children were carefully introduced to the oddity detection task. First they were asked if they could recite a rhyme. If they did not know a rhyme the experimenter recited a familiar rhyme which the child should complete ('Spieglein, Spieglein an der WAND, wer ist die Schönste im ganzen - ?'. The correct answer was 'LAND'). Then the experimenter and the child together searched for any other words that rhymed with 'LAND' and 'WAND', e.g. 'HAND', 'SAND', 'BAND' or 'RAND'. In a further step the child was told that $s$ he would hear four words of which three sounded the same, but one did not sound the same. S/he should listen to the four words carefully and then repeat the odd word. In the first practice trial the odd word was quite easy to detect because it had no similarity to the other three (SCHNEETEE-KLEE-TOR). If the child could not give the correct answer the experimenter spoke the odd word and the child had to repeat it. The experimenter again grouped the rhyming words together and explained: 'Yes, SCHNEE, TEE and KLEE belong together because they sound the same, but TOR does not sound the same, so it is the odd one out'. Two further practice trials with easily detectable odd words out followed (BETT, NETT, FETT, TIER; WAL, TAL, SAAL, TINTE). The experimenter also explained that the odd word could occur in every position by presenting the same practice trial (DACH, $\mathrm{KRACH}, L A C K, \mathrm{FACH})$ in two different sequences. After this rather extensive training the three tasks (first sound, middle sound, end sound) were presented with six items for each task. The order of the three tasks was counterbalanced. Two practice trials with feedback about the correct response preceded each task.

\section{Reading and spelling assessment at the end of grade one}

Children's reading progress at the end of grade one was assessed by having them read aloud 12 singly presented words. Six words were monosyllabic: ist, und, das, ein, Turm, Kern; six words consisted of 
more than one syllable: Birne, Vater, Feder, Domino, Lampion, Autobus. In addition, a short text consisting of 23 words had to be read aloud. Translated, this text said something like: In the old pear tree birds are building a nest out of feathers and straw. Mother bird has seven little eggs and will soon bave seven little children. All the words consisted of graphemes which were already learned during grade one (some of the more infrequent graphemes were introduced in grade two). Since word reading accuracy was known to be generally high, children's reading speed was also examined. This was done by presenting the words one at a time, at first for only about $1 \mathrm{~s}$ and taking the number of words read correctly under short-time presentation as a measure of reading speed. A second measure of reading speed was the length of time taken to read the short text. When a child in the single word reading task failed to read a word correctly under short-time presentation, the word was presented again.

To assess children's ability to assemble pronunciations for unfamiliar words, 12 non-words were presented in exactly the same way as the words (short-time presentation followed in the case of failure or error by a second presentation). The non-words were derived from the words by rearranging the graphemes of each word, but observing phonotactic rules of German (tis, nud, sad, nei, Murt, Nerk, Imeb, Verta, Derfe, Nodimo, Pamlion, Otausub).

Half of the words and the non-words used for reading were dictated to the children to examine their spelling achievement. For word spelling, the number of orthographically correct spellings was considered. A phonetic distance measure developed by Bishop (1985) was used for the evaluation of nonword spelling. A spelling received a score of $O$ if the spoken word was recoded in an appropriate way. A distance point was given for each phoneme of the spoken target which was incorrectly represented or omitted in a child's spelling. For example, the spelling Noio for 'Nodimo' got a distance score of 2 since the phonemes $/ \mathrm{d} /$ and $/ \mathrm{m} /$ were not represented.

\section{Reading and spelling assessment at the end of grade three}

At the end of grade three children's reading ability was tested again. Children read aloud a short, simple text (30 words) and three lists, one of words, and two of non-words. The main measure of interest was reading time, since number of errors was known to be very low. The word list consisted of 30 short highfrequency content words (e.g. Katze, Hut, Ball). The items of the analogous non-word list were derived from the content words by exchanging the beginnings of the words, in most cases the single consonantal onset grapheme (e.g. Natze, $\left.P_{u t}, \mathrm{Kall}\right)$. This left intact the grapheme clusters standing for the rhyme part of most of the high-frequency content words. For those three words where the onser position was empty (alt, Oma, Esel) the beginning vowels were exchanged (olt, Ema, asel). Therefore, in assembling pronunciations for these non-words children could rely on analogies to cxisting words. This stands in contrast to the items of the CV-structure non-word list. These 24 non-words exhibited simple consonant-vowel structures, mostly $\mathrm{CVCV}(\mathrm{CV})$, which are quite untypical of German words. Examples are tarulo, beleki, tanes, ketu, etc. Obviously, knowledge of ty pical orthographic structures is of little help in assembling pronunciations for these non-words. The lists of words and non-words are given in Appendix B.

A spelling test consisting of 49 words was used to assess children's spelling competence at the end of grade three. All the words had special orthographic features such as the doubling of a consonant grapheme to mark that the preceding vowel is short (e.g. Ball). Therefore, children were unlikely to produce correct spellings if they simply translated the phoneme sequence to graphemes. The children were provided with 49 sentence frames where the critical word was missing. Children's spelling of nonwords was tested by dictating 11 non-words like Trepok, Pflomo, Makrofte etc. Again Bishop's (1985) phonemic distance score was used to evaluate children's non-word spellings. Appendix B gives the words of the spelling test and also the non-words.

\section{Results}

\section{Rhyme and onset oddity detection}

Table 1 (upper section) shows that the onset task was more difficult (about 40 per cent correct) than the rhyme tasks (about 60 per cent correct in each of the latter) $(F(2,88)=$ 
Table 1. Means and standard deviations of scores on the oddity detection tasks and correlations between tasks in Study 1 (maximum score $=6$ ) and Study 2 (maximum score $=$ 10)

Tasks

Study $1(N=45)$

(1) First sound

(2) Middle sound

(3) End sound

Study $2(N=138)$

(1) First sound

(2) Middle sound

(3) End sound
(2)

(3)

Mean

$\mathrm{SD}$

.00

.13

2.5

1.3

$.49 \% 3.8$

1.6

$3.4 \quad 1.4$

$\begin{array}{llll}.27 * 6 & .39 * * \% & 4.4 & 2.1\end{array}$

$.62 * 2 \% \quad 7.4 \quad 2.2$

$7.1 \quad 2.1$

$\because p<0.01 ; \therefore \% p<.001$.

$10.9, p<.001)$. Nevertheless, performance on the more difficult onset task was well above guessing (i.e. 25 per cent correct). Table 1 also shows that the correlations between the onset task and the rhyme tasks were low, while the two rhyme tasks were substantially interrelated.

Reading and spelling at the end of grade one

As expected, the majority of children showed generally high reading accuracy. When children's correct pronunciation in their second attempts in the single word and nonword reading task were taken into account, the mean number of errors was 0.7 for words, and 1.4 for non-words ( $\max .=12$ for both words and non-words). Similarly, the mean number of errors on the text reading task was 1.8 ( $\max .=23)$. The few errors on the three tasks were combined in a composite error measure. Reading speed proved to be more discriminative. On the single word reading task the mean number correct under shorttime presentation was 8.5 for words and 6.7 for non-words. The mean reading time per word on the text was $3.2 \mathrm{~s}$. The three reading speed measures were highly associated, all correlations between .60 and .70 .

The six non-words were spelt with high accuracy as evident from the mean phonetic distance score of 2.1 . The mean number of orthographically wrong spellings ( $\max .=6$ ) was also quite low (mean $=1.6$ errors).

\section{Reading and spelling at the end of grade three}

At the end of grade three, children most often made no errors in reading the word list and the text (mean error per cents $<1$ ). More errors occurred on the non-word lists. The mean error rate was 4.8 per cent for the analogous non-words and 9.9 per cent for the $\mathrm{CV}$-structure non-words. Closer inspection of the errors on the CV-structure nonword task showed that the majority of errors were minor deviations from the target pronunciations in that only one phoneme was wrong, deleted or added (e.g. 'geligun' for gelipun or 'trarulo' for tarulo). All the errors on this task were non-words and no reading refusals occurred. The errors on all four reading tasks were combined into a composite 
error score. Children's reading of non-words was slower than their reading of words and text. The mean reading time per word for analogous non-words and CV-structure nonwords was $1.4 \mathrm{~s}$ and $1.9 \mathrm{~s}$, respectively, while for text and word reading the means were $0.5 \mathrm{~s}$ and $0.8 \mathrm{~s}$, respectively. The writing tasks also posed little difficulty. The mean phonetic distance score on the non-word spelling task was 1.5, and the mean number of orthographically wrong spellings was $7.9(\max .=49)$.

Relationship between oddity detection and reading and spelling at the end of grade one and grade three

In a first step we examined the simple and partial correlations (with Raven IQ partialled out) between the phonological awareness predictors and the reading and writing achievement scores at the end of grades one and three. Differences between simple and partial correlations were negligible, therefore Table 2 gives only the partial correlations. Because of the high correlation between the middle- and end-sound task, these two tasks were combined into a rhyme score.

Table 2 shows an interesting change from grade one to grade three in the predictive relationship between onset and rhyme oddity detection to achievement in reading and spelling. At the end of grade one the phonological awareness measures were most often only minimally related to reading and spelling. Only two of the correlations were reliable and in both cases the alliteration score was involved. This is remarkable since the possible variation of this score $(\max .=6$ ) was smaller than the variation of the rhyme score (max. $=12$ ).

At the end of grade three, the predictive relationship of onset and rhyme oddity detection to reading and spelling was quite different. The rhyme score was now substantially related to all reading and spelling measures, while not a single correlation between the onset score and the reading and spelling measures was reliable, with many of these latter correlations close to zero. As expected, the rhyme score was more strongly related to reading time for analogous non-words than to reading time for words and for $\mathrm{CV}$-structure non-words. However, even the correlations with reading time for the latter two types of words were reliable.

\section{Discussion}

The main finding of Study 1 was the developmental change in the predictive relationship of rhyme and word-onset awareness to reading and spelling achievement. While rhyme awareness tested before reading instruction was of little importance for reading and spelling achievement at the end of grade one, it was substantially related to all reading and spelling measures at the end of grade three. Just the opposite was the case for onset awareness, which was of limited importance for end of grade one achievements, and was no longer predictive for end of grade three reading and spelling achievement. Since these findings are based on a small number of children it seemed advisable to replicate them with a larger rumber of subjects. This is the aim of Study 2 .

\section{STUDY 2}

Study 2 was part of the Munich Longitudinal Study on the Genesis of Individual Competencies (Weinert \& Schneider, 1992). As in Study 1 a German version of the 
Table 2. Partial correlations (using IQ as covariate) between word-onset and rhyme detection and reading and spelling achievements in Study 1 and Study 2

\begin{tabular}{|c|c|c|}
\hline & Onset & Rhyme \\
\hline \multicolumn{3}{|l|}{ Study $1(N=45)$} \\
\hline \multicolumn{3}{|l|}{ Grade one } \\
\hline \multicolumn{3}{|l|}{ Reading } \\
\hline Text (time) & .19 & .18 \\
\hline Words (short presentation) & .23 & .14 \\
\hline Non-words (short presentation) & $.30^{*}$ & .23 \\
\hline Errors (long presentation + text) & .21 & .22 \\
\hline \multicolumn{3}{|l|}{ Spelling } \\
\hline Words (orthographic errors) & $.30 \%$ & .10 \\
\hline Non-words (phonetic distance) & .16 & .17 \\
\hline \multicolumn{3}{|l|}{ Grade three } \\
\hline \multicolumn{3}{|l|}{ Reading time } \\
\hline Text & .06 & $.49 \div \div$ \\
\hline Words & .00 & $.28 *$ \\
\hline Non-words (word-analogous) & .07 & $.46^{* * * 2}$ \\
\hline Non-words (CV-structure) & .08 & $.36 \% *$ \\
\hline Reading errors (combined) & .17 & $.32^{*}$ \\
\hline \multicolumn{3}{|l|}{ Spelling } \\
\hline Words (orthographic errors) & .19 & $.39 \div \div$ \\
\hline Non-words (phonetic distance) & .09 & $.37 \div \div$ \\
\hline \multicolumn{3}{|l|}{ Study $2(N=138)$} \\
\hline \multicolumn{3}{|l|}{ Grade one } \\
\hline \multicolumn{3}{|l|}{ Reading time } \\
\hline Words & $.34 \div \div \div$ & $.21 *$ \\
\hline Non-words & $.31 * * *$ & $.17 \div$ \\
\hline Spelling (orthographic errors) & $.25 \%$ & $.23 *$ \\
\hline \multicolumn{3}{|l|}{ Grade four } \\
\hline Spelling (orthographic errors) & $.21 *$ & $.37 \cdots$ \\
\hline
\end{tabular}

$\because p<.05 ; * p<.01 ; * * * p<.001$.

Note. All correlations were in the expected direction. Therefore, signs are not represented.

Bradley \& Bryant oddity detection task was used as a phonological awareness predictor of later reading and spelling achievement. Reading and spelling achievement were first assessed after about one year of schooling, at the beginning of second grade. Among the tests applied at the end of grade four, a spelling test was useful to examine longitudinal predictions.

Besides allowing a check of the reliability of the main findings of Study 1, Study 2 also introduced additional controls. A much larger number of subjects participated, and the version of the oddity detection task used in Study 2 was closer to the original Bradley $\&$ Bryant (1985) test than the version used in Study 1. As in the Bradley \& Bryant test there were 10 items for each task, instead of only six as in Study 1. More importantly, as in the original Bradley \& Bryant test the odd word did not share any commonality with the distractors. Another advantage of Study 2 was that the first assessment of spelling 
achievement was somewhat more extensive than in Study 1. It seemed possible that the low correlations between the phonological awareness measures and spelling achievement in Study 1 were due to the fact that children had to spell only six words and six nonwords and committed few errors.

\section{Method}

\section{Subjects}

For 138 children (nearly equal numbers of boys and girls) oddity detection scores and reading and spelling achievement scores from the end of grades one and four were available. The phonological awareness test was given about four months before children began elementary school. At that time, their mean age was $6: 0$ years (range: $5: 5-6: 5$ ). Their mean intelligence, measured by the Columbia Mental Maturity Scale (Burgemeister, Blum \& Lorge, 1972), was 108 (range: 70-145). After the first year of school, directly after the summer holidays, children's reading and spelling achievement was tested. At that time children's mean age was 7:2 years. At the end of grade four, exactly four years after the children's phonological awareness was assessed in kindergarten, spelling achievement was tested again.

\section{Oddity detection task}

As mentioned, the construction of items of the present task version corresponded very closely to the task used by Bradley \& Bryant (1985) for the 5-year-olds (see Appendix C for all items). As in Study 1 children were carefully introduced to the task format. Special attention was given to preparing children for the more difficult word-onset task. Here the experimenter began with a game similar to ' $I$ spy with my little eye'. The instruction was 'I can see something which you don't see. It begins with a " $B$ ". Do you know a word which begins with a "B"? Bank. Another word which begins with a "B"? Ball. O.K.' Again two practice trials with feedback were given at the beginning of each task. The items were presented via tape-recorder. The order of the three tasks was counterbalanced.

\section{Reading and spelling achievement}

For reading assessment after grade one children had to read aloud quickly and accurately, singly presented word or non-word items. Altogether, 30 words and 30 non-words were presented in random order on a computer screen. Reading time was measured in milliseconds, beginning from the appearance of the item on the screen until the experimenter pressed a key, just after the child completed pronunciation. All the words and non-words were monosyllabic and were presented in capital letters (about four inches high). Examples for words are Hund (dog), Wort (word), Topf (pan). Examples for non-words are Fald, Pemd, Zilt. Spelling achievement after grade one was tested by dictating to each child, individually, 18 words taken from the Bavarian basic vocabulary corpus for children. Examples are Wind, Rosine, Lokomotive, etc. At the end of grade four children had to write sentences by dictation (altogether 60 words) in a classroom spelling test. The reading and spelling materials are presented in Appendix D.

\section{Results}

\section{Rbyme and onset oddity detection}

Table 1 gives the means and standard deviations of correct responses (max. $=10$ ), and shows the correlations between the three tasks. As in Study 1 oddity detection in the first-sound task was more difficult than oddity detection in the middle-and end-sound tasks $(t(137)=13.3$ and $13.5, p<.001$, respectively). The correlations between the three tasks were higher than in Study 1. However, as in Study 1, middle- and end-sound tasks, 
which both measure rhyme awareness, were more strongy interrelated. To simplify prediction we again combined scores of the middle- and end-sound task into a rhyme score.

\section{Reading and spelling achievement}

In accord with the findings of Study 1, most children after grade one read the short words and non-words without errors. The mean reading time was $1.8 \mathrm{~s}$ for words, but $4.4 \mathrm{~s}$ for non-words. The correlation between reading time scores for words and non-words was $r(136)=.91, p<.001$. This close to perfect association shows that the processes involved in the reading of words were similar to the ones involved in the reading of non-words. The mean number of errors on the spelling test at the end of grade one was 5.6 (max. = $18)$. At the end of grade four, the mean number of spelling errors was $8.7(\max .=60)$.

\section{Relationship between oddity detection and reading and spelling achievement}

Table 2 shows the partial correlations (with IQ from the Columbia Mental Maturity Scale partialled out) between oddity detection and reading and spelling achievement. Inspection of the differences between the simple and partial correlations showed that the differences were small.

\section{Discussion}

As evident from Table 2 the correlations found in Study 2 were of similar magnitude to those found in Study 1. As in Study 1, the correlations between rhyme detection and reading and spelling measures at the end of grade one were only around .20 , while the correlations between word-onset detection and reading speed were somewhat higher. Again as in Study 1, rhyme oddity detection gained in predictive importance for orthographic spelling from end of grade one to end of grade four while onset detection did not.

\section{General discussion}

The main question addressed by this research, whether awareness of rhyme and of wordonset similarities between words is of the same importance for learning to read German as it is for learning to read English, must be answered differently for rhyme and for wordonset. The first finding suggesting such a differentiation was that in both Studies 1 and 2 rhyme oddity detection was found to be easier than onset oddity detection. A similar difference in task difficulty was observed by Bradley \& Bryant (1985). A plausible interpretation of these convergent findings of a higher difficulty of word-onset than of rhyme detection is that in the tasks of the studies mentioned word-onset is a small phonological segment (most often consisting of one consonant only), while rhyme was larger (consisting of vowel plus consonant(s)). Of course, there is no necessary connection between number of phonemes and word-onset vs. rhyme. Furthermore, Kirtley et al. (1989) have shown that the difficulty of single phoneme detection depends on whether the single phoneme constitutes a word-onset (easier to detect) or part of the rhyme (more difficult to detect). Besides the higher difficulty of word-onset detection in 
these two studies, it is also interesting to note that in both Study 1 and Study 2 the correlations between the onset detection task and each of the two rhyme detection tasks were low compared to the correlations between the two rhyme tasks. Overall, these findings suggest that the onset detection tasks measure somewhat different aspects of phonological awareness than the rhyme detection tasks. This conclusion is also suggested by the differing predictive relationships to later reading and spelling achievement. The main finding here is that rhyme awareness before school was only minimally related to end of grade one reading and spelling, but gained substantially in predictive power for the later assessment of reading and spelling achievement, while no such improvement was observed for onset awareness.

This pattern of predictions finds a plausible explanation when related to the demands of early as opposed to more advanced levels of learning to read German. As noted at the beginning of this paper, the children tested were learning to read German via a phonics approach. The goal of this approach, in the first year, is to introduce most of the grapheme-phoneme correspondences, and to teach and practise word recognition via grapheme-phoneme translation and blending. The generally high reading accuracy of the children tested, even for non-words at the end of grade one, shows that most children have achieved the essentials for this approach. For easy acquisition of graphemephoneme correspondences and of the indirect word recognition strategy, it seems important that the child gains awareness of how spoken words are composed of phonemes, while awareness of larger phonological segments may not be directly involved. For example, if a child cannot identify the sounds associated with the letters as phonemes of known words, then remembering grapheme-phoneme correspondences becomes quite difficult, since it amounts to associating artificial articulatory gestures with letters. Similarly, blending of phonemes becomes a laborious articulatory exercise, when top-down constraints from spoken words are not effective. For example, to blend $/ b /$ and $/ 1 /$ in reading 'Blume' may be difficult when $/ b /$ followed by $/ 1 /$ cannot be matched with the given representation of a phonemically segmented word onset $/ \mathrm{bl}-1$. That an emerging awareness of the phonemic composition of words is, in fact, critically involved in the early phase of learning to read German, was shown in previous research from the Salzburg laboratory (Wimmer \& Hummer, 1990; Wimmer, Landerl, Linortner \& Hummer, 1991). Wimmer et al. found substantial correlations between phoneme awareness (measured with a vowel substitution task before school) and reading and spelling achievement at the end of grade one, even when IQ and early letter knowledge were partialled out. Wimmer \& Hummer found that children with reading delays at the end of grade one had difficulties with phonemic segmentation, as evident from their particularly weak performance on a non-word spelling task.

Why rhyme awareness gained substantially in predictive importance for reading and spelling achievement at the end of grade three and four can be explained by its role in achieving reading fluency and high levels of orthographic skills. The present results give evidence for such progress in reading and spelling. For example, speed of text reading has improved from a slow $3.3 \mathrm{~s}$ per word in grade one to $0.5 \mathrm{~s}$ in grade three (Study 1), and overall the orthographic spelling skills were impressive with not more than about 15 per cent wrong spellings in grade three (Study 1) or grade four (Study 2). We propose that awareness of larger phonological segments such as rhymes affects reading fluency, and orthographic spelling skills, by affecting children's ability to build up memory 
representations for written words. Such memory representations function as recognition units in reading where they allow direct access to pronunciation and meaning. Such representations also guarantee orthographically correct spellings. We assume that such representations for written words are more easily built up in memory when multiple connections to phonology are established. (The general idea of word representations with multiple and redundant connections to phonology is borrowed from Perfetti, 1992.) There are at least two relevant phonological levels. First is the phonemic level of spoken words. Here, connections can be established between the graphemic constituents of the mental representation of written words, and the phonemic constituents of the mental representations of spoken words. Second is the level of syllable constituents such as consonantal onsets, syllable-rimes and consonantal endings of rimes. These constituents of syllables seem to be of particular importance, since there are grapheme clusters of high frequency which map consistently on such phonological units. In words like Hand, Wand, Sand or Mund, rund, Hund the common grapheme clusters conform to the rime. Particularly frequent are word endings like -er (e.g. Wasser, Bauer, Fahrer) and -en (e.g. Garten, malen, singen), which, in the examples given, correspond to the rime of the second syllable. Certain clusters of consonant graphemes corresponding to onsets and endings of syllables are also quite frequent. Examples of the former are $B l-$ (Blume, Blase) or Str-(Strasse, Strand), examples of the latter are-nd (Hand, Wind) or - $m p f$ (Kampf, Sumpf). Such phonologically guided clustering of graphemes may be better achieved by children who already, before school, show high levels of rhyme awareness. The clustering of graphemes allows a more economical representation of written words in memory by providing hierarchical structure to the representation and by providing additional connections to phonology. Furthermore, such representations with phonologically underpinned grapheme clusters allow 'analogical' processes in reading and writing of new words. For example, for reading the new word Pfund (pound) the grapheme cluster -und in the existing representations for Hund and Mund may be activated and provide the correct pronunciation.

The conclusion, then, is that at least rhyme awareness was found to be of similar relevance for learning to read German as it was found for learning to read English. The difference is that for learning to read English rhyme awareness was found to be important from the very beginning, while for learning to read German rhyme awareness became important considerably later. The hypothesized underlying common factor is direct word recognition. This mode of recognition via mental representations of written words is an issue in learning to read English from the very beginning, since the inconsistency of the English orthography makes indirect word recognition difficult and error-prone. In contrast, the consistency of the German orthography allows an easy and successful start into reading via indirect word recognition (i.e. grapheme-phoneme translation and blending). Here, direct word recognition becomes important when automatized word recognition and reading fluency has to be acquired. For some time the direct mode of word recognition was conceptualized as depending solely on a heavy dose of reading experience and on visual memory for written words. Lately, it has been argued on both theoretical and empirical grounds that phonological factors are involved in the establishment and use of mental representations of written words (Ehri, 1992; Perfetti, 1992; Stuart \& Coltheart, 1988). The present finding that early rhyme awareness becomes predictive not for success with early indirect word recognition, but for success 
with later direct word recognition and orthographic spelling, constitutes strong evidence for the phonological view of direct word recognition.

\section{Acknowledgements}

The present research was supported by a grant from the Austrian Science Foundation (grant number P7277-SPR). We are grateful to two reviewers for their comments on earlier versions of the present paper.

\section{References}

Bishop, D. V. M. (1985). Spelling ability in congenital dysarthria: Evidence against articulatory coding in translating between phonemes and graphemes. Cognitive Neuropsychology, 2, 229 251.

Bradley, L. \& Bryant, P. E. (1978). Difficulties in auditory organisation as a possible cause of reading backwardness. Nature, 271, 746-747.

Bradley, L. \& Bryant, P. E. (1985). Rhyme and Reason in Reading and Spelling. Ann Arbor, MI: University of Michigan Press.

Bryant, P. E., MacLean, M., Bradley, L. \& Crossland, J. (1990). Rhyme and alliteration, phoneme detection and learning to read. Developmental Psychology, 26, 429-438.

Burgemeister, B., Blum, L. \& Lorge, J. (1972). Columbia Mental Maturity Scale. New York: Harcourt Brace Jovanovich.

Ehri, L. C. (1992). Reconceptualizing the development of sight word reading and its relationship to recording. In P. B. Gough, L. C. Ehri \& R. Treiman (Eds), Reading Acquisition, pp. 107-143. Hillsdale, NJ: Erlbaum.

Goswami, U. (1986). Children's use of analogy in learning to read: A developmental study. Journal of Experimental Child Psychology, 42, 73-83.

Goswami, U. (1988). Children's use of analogy in learning to spell. British Journal of Experimental Psychology, 6, 21-33.

Goswami, U. (1990). A special link berween rhyming skills and the use of orthographic analogies by beginning readers. Journal of Child Psychology and Psychiatry, 31, 301-311.

Goswami, U. (1991). Learning about spelling sequences: The role of onsets and rimes in analogies in reading. Child Development, 62, 1110-1123.

Kirtley, C., Bryant, P., MacLean, M. \& Bradley, L. (1989). Rhyme, rime and the onset of reading. Journal of Experimental Child Psychology, 48, 224-245.

Perfetti, C. (1992). The representation problem in reading acquisition. In P. B. Gough, L. C. Ehri \& R. Treiman (Eds), Reading Acquisition, pp. 145-174. Hillsdale, NJ: Erlbaum.

Stuart, M. \& Coltheart, M. (1988). Does reading develop in a sequence of stages? Cognition, 30, 139-181.

Weinert, F. \& Schneider, W. (1992). The Munich Longitudinal Study on the Genesis of Individual Competencies (LOGIC). Report No. 8: Assessment Procedures and Results of Wave Five. Munich: Max-Planck Institute for Psychological Research.

Wimmer, H. \& Frith, U. (1992). Orthographies and learning to read: An English-German comparison. Unpublished manuscript, University of Salzburg.

Wimmer, H. \& Goswami, U. (1994). The influence of orthographic consistency on reading development: Word recognition in English and German children. Cognition, 51, 91-103.

Wimmer, H. \& Hummer, P. (1990). How German speaking first graders read and spell: Doubts on the importance of the logographic stage. Applied Psycholinguistics, 11, 349-368.

Wimmer, H., Landerl, K., Linortner, R. \& Hummer, P. (1991). The relationship of phonemic awareness to reading acquisition: More consequence than precondition but still important. Cognition, 40, 219-249. 


\section{Appendix A}

\section{Study 1: Oddity detection task}

First sound:

$\begin{array}{llll}\text { SAFT } & - \text { SALZ } & - \text { PFAND } & - \text { SAND } \\ \text { RUF } & - \text { RUND } & - \text { RUM } & - \text { STUMM } \\ \text { RAD } & - \text { LAST } & - \text { RAHM } & - \text { RAST } \\ \text { SEIL } & - \text { WEIN } & - \text { WEISS } & - \text { WEIL } \\ \text { BACH } & - \text { BAHN } & - \text { DACH } & - \text { BAD } \\ \text { STOCK } & - \text { STOFF } & - \text { STOSS } & - \text { ROCK } \\ \text { Middle sound: } & & & \\ \text { MUND } & - \text { RUND } & - \text { MOND } & - \text { HUND } \\ \text { BRAV } & - \text { SCHLAF } & - \text { BRIEF } & - \text { SCHAF } \\ \text { BACH } & - \text { FACH } & - \text { DACH } & - \text { BUCH } \\ \text { STRICK } & - \text { BLOCK } & - \text { BLICK } & - \text { TRICK } \\ \text { FASS } & - \text { GUSS } & - \text { MUSS } & - \text { SCHUSS } \\ \text { SCHWER } & - \text { SEHR } & - \text { MEER } & - \text { MOOR } \\ \text { End sound: } & & & \\ \text { HAND } & - \text { SAND } & - \text { WAND } & - \text { TANK } \\ \text { BOOT } & - \text { TOR } & - \text { MOOR } & - \text { VOR } \\ \text { BETT } & - \text { NETT } & - \text { SCHECK } & - \text { FETT } \\ \text { WITZ } & - \text { FRITZ } & - \text { SCHLITZ } & - \text { FINK } \\ \text { KAMM } & - \text { SCHWAMM } & - \text { MATT } & - \text { LAMM } \\ \text { MEER } & - \text { MEHL } & - \text { SEHR } & - \text { LEER }\end{array}$

\section{Appendix B}

\section{Study 1: Material for reading and spelling assessment at the end of grade three}

\section{Reading}

Frequent words:

Katze, alt, Hut, Ball, Esel, Heft, Papa, Buch, jetzt, Schnee, Nase, viel, Oma, Schule, Tür, Maus,

Bett, Mutter, Strasse, Brief, Tag, Stein, Tante, Zeit, Mann, Sonne, Puppe, klein, Leute, Küche

Analogous non-words:

Natze, Olt, Put, Kall, asel, Teft, Hapa, Luch, Tetzt, Mee, Sase, Hiel, Ema, Mule, Bür, Kaus, Schett,

Stutter, jasse, klief, Pag, Zein, Bante, Beit, vann, Stronne, Muppe, Brein, Schneute, Tüche

CV-Structure non-words:

Tarulo, heleki, tokal, surime, ketu, rateka, sarite, tanes, fukuno, tolaka, kelitun, sakole, kisul, Spelling

nikatal, matak, utina, refeku, nateli, tewanu, onak, neraf, tikosa, remo, aroni

Words:

Hand, Garten, Wälder, Mutter, sprechen, Kind, Wasser, Sack, See, Bild, geht, Sonne, Bären, Brot, kommt, Blatt, warm, Häuser, Ball, ihm, steigt, fehlen, schläft, Jahr, nur, setzt, lassen, versuchen, Boot, schmeckt, wann, ohne, Meer, stricken, Kerze, Zahlen, kennt, Vorraum, sieht, versprochen, Haare, schluckt, Österreich, spitzt, früh, trank, fliesst, verraten, Arzt

Non-words:

Buri, Trepok, Pflomos, Strakli, Somemot, Klanuchas, Makrofte, Proklechtof

\section{Appendix C}

\section{Study 2: Oddity detection task}

First sound:

$\begin{array}{llll}\text { TAL } & - \text { TAT } & - \text { TAG } & -R A D\end{array}$ 


$\begin{array}{llll}\text { BURG } & - \text { BUCH } & - \text { LUFT } & - \text { BUSCH } \\ \text { HALS } & - \text { BANK } & - \text { HANG } & - \text { HAND } \\ \text { STOCK } & - \text { STOLZ } & - \text { POST } & - \text { STOFF } \\ \text { KORN } & - \text { KOPF } & - \text { KORB } & - \text { ROCK } \\ \text { SAFT } & - \text { BACH } & - \text { SAND } & - \text { SACK } \\ \text { LAST } & - \text { STALL } & - \text { STADT } & - \text { STAND } \\ \text { FEST } & - \text { FELD } & - \text { FELS } & - \text { HELM } \\ \text { GAST } & - \text { HALT } & - \text { GANS } & - \text { GANG } \\ \text { Middle sound: } & & & \\ \text { NEST } & - \text { FEST } & - \text { REST } & - \text { LUST } \\ \text { BUS } & - \text { FASS } & - \text { NUSS } & - \text { KUSS } \\ \text { HUND } & - \text { WIND } & - \text { KIND } & - \text { RIND } \\ \text { KREIS } & - \text { PREIS } & - \text { GRAS } & - \text { FLEISS } \\ \text { HAND } & - \text { WAND } & - \text { LAND } & - \text { KIND } \\ \text { TURM } & - \text { LARM } & - \text { STURM } & - \text { WURM } \\ \text { HAHN } & - \text { SOHN } & - \text { LOHN } & - \text { MOHN } \\ \text { MUT } & - \text { WUT } & - \text { RAT } & - \text { HUT } \\ \text { BUND } & - \text { HUND } & - \text { WAND } & - \text { MUND } \\ \text { FALL } & - \text { WALL } & - \text { HALL } & - \text { DILL } \\ \text { End SOUnd: } & & & - \text { RAUM } \\ \text { SAUM } & - \text { BAUM } & - \text { LAUT } & - \text { FELD } \\ \text { BETT } & - \text { HELD } & - \text { GELD } & - \text { - LAUS } \\ \text { HAUS } & - \text { BAUM } & - \text { MAUS } & - \text { TEIG } \\ \text { STEIN } & - \text { WEIN } & - \text { BEIN } & - \text { PARK } \\ \text { STALL } & - \text { MARK } & - \text { QUARK } & - \text { KAHN } \\ \text { ZAHN } & - \text { HAHN } & - \text { TAL } & - \text { LAND } \\ \text { HAND } & - \text { BART } & - \text { SAND } & - \text { LAN } \\ \text { SPECK } & - \text { DRECK } & - \text { STERN } & - \text { FLECK } \\ \text { ZOPF } & - \text { TOPF } & - \text { KOPF } & - \text { DORF } \\ \text { KUSS } & - \text { LUFT } & - \text { BUS } & - \text { SCHLUSS }\end{array}$

\section{Appendix D}

\section{Study 2: Reading and spelling material}

After grade one

Reading

Words: Hund, hier, Wort, neun, fast, Topf, Brot, drei, Senf, nach, Korb, dein, Dank, euch, Gans, fast, Heft, acht, blau, Hand, sich, Zelt, tief, Hemd, Wald, Tisch, Schwanz, echt, Sicht, kein, Freund, glaubt, klein, nicht, hilft

Non-words: Fald, kert, Mopf, isch, Kast, icht, Gest, Dand, glau, spei, Zilt, wanz, Fult, Frot, welz, Pemd, irsk, Fils, lein, Kort, Penf, kieg, Wist, bans, eund, Mank, lich, salt, empf Spelling

Words: nachher, Reifen, Hauben, demnach, hervor, reiben, Haufen, vordem, Haus, Kanu, Rosine, Schimmel, Leiter, Wand, billig, Lokomotive, Strumpf

End of grade four

Sentences used for spelling assessment: ${ }^{a}$

Wimpeln flattern am Fahrrad.

Grüne Srassen fallen viel.

Mein Strumpf schmeckt süss.

Sessel sind bequem.

Lokomotiven stehlen Fleisch.

Familie Müller sitzt beim Frühstück.

Nachher singen wir. 
Max bekommt ein Päckchen zum Geburtstag.

Wohnungen verstehen Spass.

Das Eichhörnchen knackt Nüsse.

Schimmel sind Pferde.

Der Torwart schimpft mit dem Schiedsrichter.

Weihnachten ist im Frühling.

Die Lehrerin schreibt am Computer.

"To make the task more attractive children were told that some of the sentences described 'impossible' events. 